\title{
Phospholipase $\mathbf{C}$ activation by ethanol in rat hepatocytes is unaffected by chronic ethanol feeding
}

\author{
Jan B. HOEK,* Theodore F. TARASCHI, Katsuyoshi HIGASHI, Emanuel RUBIN and Andrew P. THOMAS \\ Department of Pathology and Cell Biology, Thomas Jefferson University, Philadelphia, PA 19107, U.S.A.
}

\begin{abstract}
The activation of phosphoinositide-specific phospholipase $\mathrm{C}$ by ethanol was compared in hepatocytes isolated from ethanol-fed rats and from pair-fed control animals. Ethanol (100-300 mM) caused a dose-dependent transient increase in cytosolic free $\mathrm{Ca}^{2+}$ levels in indo-1-loaded hepatocytes from both groups of animals. The rate of $\mathrm{Ca}^{2+}$ increase was similar in hepatocytes from control and ethanol-fed rats, but the decay of the $\mathrm{Ca}^{2+}$ increase was somewhat slower in the latter preparation. The ethanol-induced $\mathrm{Ca}^{2+}$ increase caused activation of glycogen phosphorylase, with $50 \%$ response at 50 mM-ethanol and a maximal response at 150-200 mM-ethanol, not significantly different in hepatocytes from control and ethanol-fed animals. Ins $(1,4,5) P_{3}$ formation in response to ethanol $(300 \mathrm{~mm})$ or vasopressin $(2 \mathrm{nM}$ or $40 \mathrm{nM})$ was also similar in the two preparations. It is concluded that long-term ethanol feeding does not lead to an adaptive response with respect to the ethanol-induced phospholipase $\mathrm{C}$ activation in rat hepatocytes. The ability of ethanol in vitro to decrease membrane molecular order in liver plasma membranes from ethanol-fed and control rats was measured by e.s.r. Membranes from ethanol-fed animals had a significantly lower baseline order parameter compared with control preparations ( 0.313 and 0.327 respectively), indicative of decreased membrane molecular order. Addition of $100 \mathrm{~mm}$ ethanol significantly decreased the order parameter in control preparations by $2.1 \%$, but had no effect on the order parameter of plasma membranes from ethanol-fed rats, indicating that the plasma membranes had developed tolerance to ethanol, similar to other membranes in the liver. Thus the membrane structural changes associated with this membrane tolerance do not modify the ethanol-induced activation of phospholipase $\mathrm{C}$. The transient activation of phospholipase $\mathrm{C}$ by ethanol in hepatocytes may play a role in maintaining an adaptive phenotype in rat liver.
\end{abstract}

\section{INTRODUCTION}

Long-term ethanol intake in rats and other animals causes adaptive changes in different tissues at the cellular and subcellular levels, allowing the system to function normally in the presence of significant circulating concentrations of ethanol (which may be in the order of $25-50 \mathrm{~mm}$ ) [1]. These adaptive responses generally involve processes which are affected by ethanol in vitro, ranging from specific enzyme activities (e.g., $\mathrm{Na}^{+} / \mathrm{K}^{+}$-ATPase, monoamine oxidase [2]), to complex integrated functions, such as oxidative phosphorylation and transmembrane signal transduction $[1,3,4]$. Many of the processes affected by ethanol are membrane-associated; hence the ability of ethanol to interact with biological membranes has been proposed to be an essential element in these adaptive responses [1,3]. In support of this model, there is considerable evidence that long-term intake of ethanol by the rat results in significant changes in the physical characteristics of biological membranes. Specifically, isolated membranes from liver, brain, pancreas or erythrocytes of ethanolfed animals demonstrate a decreased sensitivity to membrane disordering by ethanol in vitro. The molecular basis for this 'membrane tolerance' $[1,3]$ has not yet been identified; however, previous studies from our laboratory have established that the underlying cause may be related to chemical changes in negatively charged phospholipids [5-7]. Further evidence of altered membrane structure is the decreased partitioning of ethanol and other anaesthetics into membranes from ethanol-fed animals. This difference may be partly responsible for the apparent tolerance to ethanol of many membrane-bound enzyme activities in the intact cell.

Previously we have demonstrated that ethanol added in vitro induces a transient activation of the phosphoinositide-specific phospholipase $C$ in intact hepatocytes and other cell types [8-10]. Ethanol, in concentrations of $25-300 \mathrm{~mm}$, mimicked the action of hormones in causing the formation of $\operatorname{Ins}(1,4,5) P_{3}$, with a consequent increase in cytosolic $\mathrm{Ca}^{2+}$ and the activation of $\mathrm{Ca}^{2+}$. dependent enzymes, such as phosphorylase kinase in liver [8]. This activation of the signal-transduction system appears to bypass the receptors which normally control the phospholipase $\mathrm{C}$ activity in these and other cells. Mechanistic studies were carried out in isolated turkey erythrocyte membranes, a suitable model membrane system showing a similar ethanol-sensitivity of the polyphosphoinositide-linked phospholipase C [11]; these studies indicated that ethanol altered the affinity for guanine nucleotides of a G-protein that controls phospholipase C activity [11].

In several cell types, the action of ethanol on the phospholipase$\mathrm{C}$-mediated signalling system could be mimicked by longer-chain alcohols and other membrane-active agents. Increasing potency of these agents correlated with higher partitioning into biological membranes $[8,11,12]$. Hence it was postulated that this effect of ethanol is due to interference with lipid-protein or proteinprotein interactions in the membrane. We have therefore tested whether long-term ethanol feeding of the rat affects the sensitivity of hepatocytes in responding to ethanol in vitro with an activation of the hormone-sensitive phospholipase $\mathrm{C}$ activity. The results shown in this study demonstrate that the ethanol-induced activation of this signal-transduction process in hepatocytes is maintained in cells from ethanol-fed rats, despite the development of membrane tolerance in liver plasma-membrane preparations from these animals. The mechanistic and physiological implications of these findings are discussed.

Abbreviations used: SA 12, 12-[ $\beta$-(4', $4^{\prime}$-dimethyloxazolidinyl- $N$-oxyl)]stearic acid; TPEN, $N N N^{\prime} N^{\prime}$-tetrakis-(2-pyridylmethyl)ethylenediamine.

* To whom correspondence and reprint requests should be addressed. 


\section{MATERIALS AND METHODS}

Animals

Male Sprague-Dawley rats, initially weighing 120-130 g, were fed on a nutritionally adequate ethanol-containing liquid diet (Bioserv, Frenchtown, NJ, U.S.A.) for 40-45 days, as described in [13]. Littermate controls of similar body weights were pair-fed on the same liquid diet, except that ethanol was replaced by carbohydrate. Ethanol consumption averaged $14-16 \mathrm{~g} / \mathrm{kg}$ body wt. per day. Blood alcohol levels in the ethanol-fed animals averaged $25-50 \mathrm{~mm}$.

\section{Preparations and incubation conditions}

Isolated hepatocytes. These were prepared by collagenase perfusion and incubated in a Krebs-Ringer bicarbonate buffer containing $1.3 \mathrm{~mm}$ - or $2 \mathrm{~mm}-\mathrm{CaCl}_{2}, 10 \mathrm{~mm}-$ Hepes and $2 \%(\mathrm{w} / \mathrm{v})$ BSA, as described previously [8]. For inositol phosphate measurements, cells were prelabelled with myo- $\left[{ }^{3} \mathrm{H}\right]$-inositol for $90 \mathrm{~min}$ before incubation, and reactions were stopped with $\mathrm{HClO}_{4}$ as described previously [8]. For phosphorylase determinations, cells were preincubated for $30 \mathrm{~min}$ in the standard medium at $37^{\circ} \mathrm{C}$ before addition of ethanol or agonist, and reactions were stopped with a stopping medium containing $\mathrm{NaF}(50 \mathrm{~mm}), \beta$-glycerophosphate (25 mM), Mes (10 mM), EDTA ( $2 \mathrm{mM})$ and digitonin (0.2 $\mathrm{mM})$, as described previously [8]. For fluorescence assays, cells were loaded with indo- 1 by a 40 min preincubation with indo-1 AM (the penta-acetoxymethyl ester; $5 \mu \mathrm{M}$ ) in the presence of $0.0012 \%$ Pluronic F-127, followed by a $15 \mathrm{~min}$ incubation in standard incubation buffer, containing $0.2 \%$ BSA. Indo-1loaded cells were kept on ice, washed just before use to remove extracellular dye, and incubated in the cuvette of a Perkin-Elmer MPF-44B fluorimeter at $37^{\circ} \mathrm{C}$.

Plasma-membrane preparation. Plasma membranes were prepared from rat livers after a brief $(15 \mathrm{~min})$ perfusion at $37^{\circ} \mathrm{C}$ with Krebs-Ringer bicarbonate buffer to remove circulating blood cells. Just before homogenization, the liver was perfused for $1 \mathrm{~min}$ with ice-cold homogenization buffer composed of $25 \mathrm{~mm}$-sucrose, $5 \mathrm{~mm}$-Hepes and $1 \mathrm{~mm}$-EGTA at pH 7.5. Homogenization was performed by 10 passes with a loose-fitting glass Dounce homogenizer, followed by 10 passes with a tight-fitting homogenizer. The initial homogenate was diluted to give $6 \%$ $(w / v)$ based on the initial wet weight of the excised liver. After filtering through a gauze mesh, the homogenate was centrifuged at $1500 \mathrm{~g}$ for $10 \mathrm{~min}$. The pellet was resuspended in the original volume of fresh homogenization medium, and Percoll was added to give $13 \%(\mathrm{v} / \mathrm{v})$ final dilution. This suspension was centrifuged at $35000 \mathrm{~g}$ for $40 \mathrm{~min}$, yielding two bands in the upper part of the Percoll gradient. The top band, which is derived from the nuclear fraction, was discarded. The second band, containing the plasma membranes, was removed and diluted in 5 vol. of $25 \mathrm{~mm}$ sucrose/1 mM-EDTA/50 mM-Tris/Hepes, pH 7.5. The membranes were pelleted by spinning at $35000 \mathrm{~g}$ for $20 \mathrm{~min}$ and then washed twice in the same buffer. The final plasma-membrane suspension was stored frozen in liquid $\mathrm{N}_{2}$ until used. Protein was measured with a kit from Bio-Rad. Membranes prepared by this procedure were enriched 25-30-fold in the plasma-membrane marker enzyme 5'-nucleotidase, measured by the method of Bygrave \& Trauter [14], whereas contamination by microsomes and mitochondrial membranes is minimal [15].

\section{Assays}

$\mathrm{Ca}^{2+}$ measurements. For indo-1-loaded cells these were carried out in a Perkin-Elmer MPF-44B spectrofluorimeter at a wavelength pair of $340 / 395 \mathrm{~nm}$. All incubations contained 10-100 $\mu \mathrm{M}-$ TPEN in order to remove quenching by intracellular heavy- metal ions, as recommended by Arslan et al. [16]. 4-Methylpyrazole $(10 \mathrm{~mm})$, a potent inhibitor of alcohol dehydrogenase, was added to all incubations to prevent interference by ethanolinduced redox changes. Saturation fluorescence levels were determined at the end of each incubation by the addition of ionomycin $(20 \mu \mathrm{M})$ in the presence of $4 \mathrm{mM}-\mathrm{CaCl}_{2}$, and calibration of the indo-1 fluorescence was obtained by the addition of a known amount of the indo- $1 \mathrm{~K}^{+}$salt.

Inositol phosphates. These were determined by h.p.l.c. in the neutralized $\mathrm{HClO}_{4}$ extracts as described previously [8].

Phosphorylase $a$ and total phosphorylase. These activities were measured by the method of Gilboe et al. [17], as described by Uhing et al. [18], with some modifications, as detailed previously [8].

Protein. This was determined by the biuret method. In cells from ethanol-fed animals interference by triacylglycerols was corrected for by measuring the absorbance after addition of cyanide to each sample.

\section{Isolation and analysis of phospholipids}

Total lipids were extracted as described by Bligh \& Dyer [19]. Phospholipids were separated from neutral lipids on a silicic acid column [20], and stored in chloroform at $-20^{\circ} \mathrm{C}$ under $\mathrm{N}_{2}$. All procedures were performed under $\mathrm{N}_{2}$ to prevent lipid oxidation.

\section{Preparation and spin labelling of plasma-membrane phospholipids}

Multilamellar vesicles of plasma-membrane phospholipids were prepared by drying of a chloroform solution containing the desired phospholipid mixture under $\mathrm{N}_{2}$, high-vacuum desiccation of the dried lipid film for $30 \mathrm{~min}$, and hydration with phosphatebuffered saline (120 mM- NaCl/2.7 mM-KCl/10 mM-sodium phosphate), $\mathrm{pH} 7.2$. The fatty acid spin probe $12-\left[\beta-\left(4^{\prime}, 4^{\prime}\right.\right.$-dimethyloxazolidinyl- $N$-oxyl)]stearic acid (SA 12) was incorporated into the reconstituted membranes as described previously [20]. The molar ratio of membrane phospholipid/spin probe was $20: 1$.

\section{E.s.r. spectroscopy}

The spin-labelled sample, after addition of the appropriate amount of ethanol, was vortex-mixed for $2 \mathrm{~min}$ at room temperature, transferred to a $100 \mu \mathrm{l}$ capillary tube and flame-sealed. Capillary tubes were placed in an IBM Instruments ER 200D e.s.r. spectrometer cavity in a standard $4 \mathrm{~mm}$ quartz tube, which contained silicone oil to maintain thermal stability. All samples were equilibrated for $7 \mathrm{~min}$ in the cavity at $37^{\circ} \mathrm{C}$, before recording the spectrum. Temperatures were accurate to $0.5^{\circ} \mathrm{C}$. Spectra were accumulated with an IBM 9000 computer interfaced to the spectrometer. The molecular order parameter, $S$, was calculated as described previously [20]. Typical spectrometer settings were: spectral scan, $100 \mathrm{G}\left(10^{-2} \mathrm{~T}\right)$; modulation amplitude, $1.0 \mathrm{G}$ $\left(10^{-4} \mathrm{~T}\right)$; microwave power, $5 \mathrm{~mW}$. All measurements were made at $37^{\circ} \mathrm{C}$.

\section{Statistical significance}

This was calculated by Student's $t$ test. Results are expressed as the mean \pm S.E.M. for three or more individual experiments.

\section{Materials}

Spin probes, indo- $1\left(\mathrm{~K}^{+}\right.$salt) and indo-1 AM were purchased from Molecular Probes; ionomycin was obtained from Calbiochem. Radiochemicals were purchased from Amersham International; myo- $\left[2-{ }^{3} \mathrm{H}\right]$ inositol $(15 \mathrm{Ci} / \mathrm{mmol}$ in $95 \%$ ethanol) was purified as described previously [8]. Other chemicals and 
biochemicals were obtained from Sigma Chemical Co. or Fisher Scientific Co.

\section{RESULTS}

Isolated hepatocytes from control and ethanol-fed rats were loaded with the $\mathrm{Ca}^{2+}$ indicator indo- 1 for the analysis of changes in cytosolic $\mathrm{Ca}^{2+}$ level in response to ethanol and other agonists. In resting cells, the concentration of cytosolic $\mathrm{Ca}^{2+}$ was not significantly different in the two preparations: $237 \pm 10 \mathrm{nM}$ in control cells and $249 \pm 12 \mathrm{nM}$ in cells from ethanol-fed animals $(n=5)$. Figs. 1 and 2 illustrate the dose-dependent changes in cytosolic $\left[\mathrm{Ca}^{2+}\right]$ in indo-1-loaded hepatocytes induced by the addition of different amounts (100-300 mM) of ethanol. The fact that relatively high levels of ethanol were required to generate a marked increase in indo- 1 fluorescence reflects an inhibitory effect of TPEN used in these experiments to suppress the quenching effect of intracellular heavy-metal ions (K. Higashi \& J. B. Hoek, unpublished work). In the absence of TPEN, a significant increase in cytosolic free $\mathrm{Ca}^{2+}$ was found at $30 \mathrm{mM}-$ ethanol, with similar rates in preparations from control and ethanol-fed animals. The kinetics of indo-1 fluorescence changes
Control

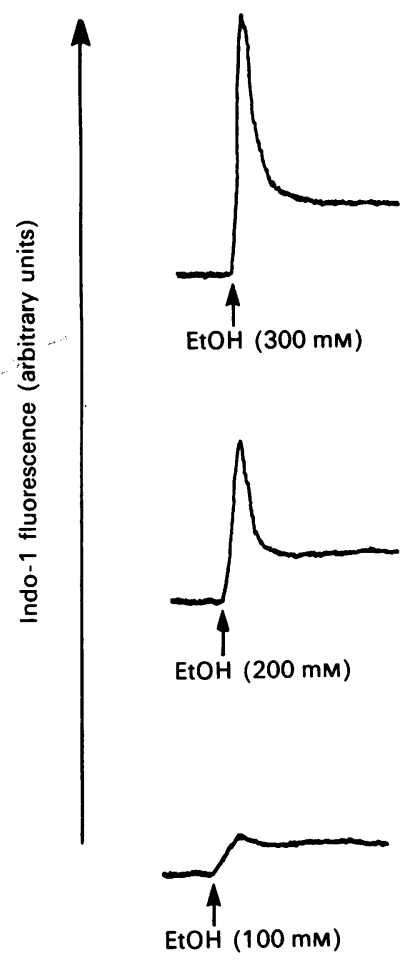

$\stackrel{\leftrightarrow \min }{\longmapsto}$
Ethanol-fed
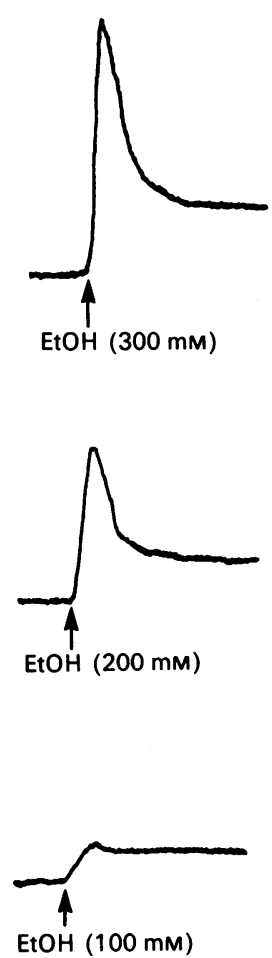

$\stackrel{\longmapsto \min }{\longmapsto}$
Fig. 1. Ethanol-induced $\mathrm{Ca}^{2+}$ mobilization in indo-1-loaded hepatocytes from ethanol-fed and control rats

Indo-1-loaded cells were incubated at $37^{\circ} \mathrm{C}$ in a fluorimeter cuvette in the standard incubation medium, containing BSA $(0.25 \%)$, TPEN $(100 \mu \mathrm{M})$ and 4-methylpyrazole $(10 \mathrm{mM})$, at a concentration of $1.7 \times 10^{6}$ cells $/ \mathrm{ml}$. After a stable baseline fluorescence signal was obtained, ethanol (EtOH) was added in the concentrations indicated. Traces with cells from control and ethanol-fed rats were normalized to the total indo-1 fluorescence in each incubation, obtained after addition of ionomycin $(20 \mu \mathrm{M})$.

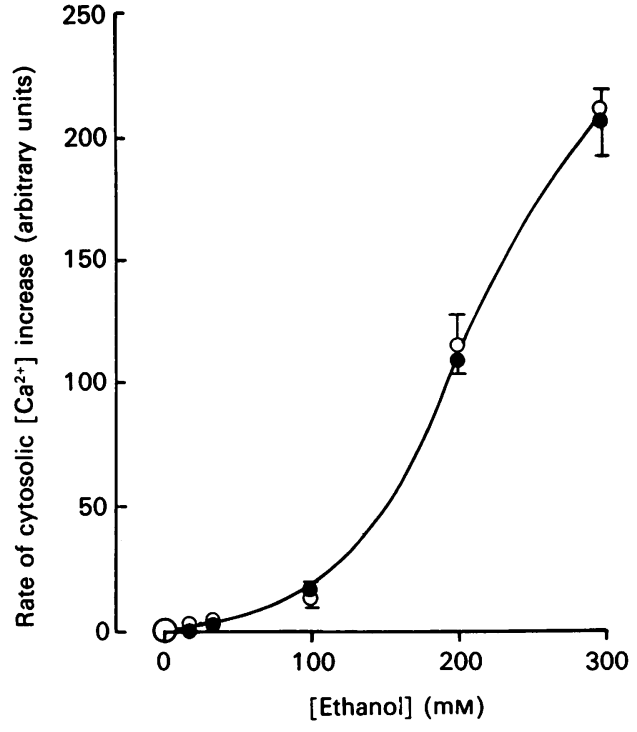

Fig. 2. Efiect of ethanol concentration on the initial rate of $\mathrm{Ca}^{2+}$ mobilization in indo-1-loaded hepatocytes

Incubation conditions were as described for Fig. 1: $O$, control preparations; 0, preparations from ethanol-fed rats. Error bars indicate means \pm S.E.M. for three or four individual pairs.

induced by ethanol were essentially identical in both types of preparation. Ethanol caused a rapid increase in $\mathrm{Ca}^{2+}$, which reached a peak after about 20-30 s, and was followed by a decline over a period of 1-2 min to a steady-state level that was only slightly elevated over the basal level. The rate of increase in cytosolic $\mathrm{Ca}^{2+}$ in response to $300 \mathrm{~mm}$-ethanol was estimated at $1.94 \pm 0.02$ and $1.82 \pm 0.08 \mathrm{nmol}$ of $\mathrm{Ca}^{2+} / \mathrm{min}$ per $10^{6}$ cells in preparations from control and ethanol-fed animals respectively $(n=3)$. The dose-response curve for the rate of ethanol-induced $\mathrm{Ca}^{2+}$ mobilization, as detected by indo-1 fluorescence, was not significantly different in these preparations (Fig. 2). However, the rate of decay of the $\mathrm{Ca}^{2+}$ signal was slower in the hepatocytes from ethanol-fed rats. In six pairs, with $300 \mathrm{~mm}$-ethanol the peak width at half-maximal $\mathrm{Ca}^{2+}$ elevation was $23 \pm 1 \mathrm{~s}$ for control hepatocytes and $39 \pm 3 \mathrm{~s}$ for cells from ethanol-fed animals $(P<0.01)$. In a previous study [21], we demonstrated that the decay of the $\mathrm{Ca}^{2+}$ response to ethanol may reflect feedback inhibition by protein kinase $\mathrm{C}$. Hence the cells from ethanol-fed animals may differ from the control animals in being less susceptible to this inhibitory effect of protein kinase $\mathrm{C}$.

The increased cytosolic $\mathrm{Ca}^{2+}$ caused by ethanol is also equally effective in activating intracellular $\mathrm{Ca}^{2+}$-sensitive enzymes. This is demonstrated in Fig. 3, where the activity of glycogen phosphorylase was measured in cells treated with different concentrations of ethanol. Phosphorylase activation is due to the $\mathrm{Ca}^{2+}$-dependent activation of phosphorylase kinase and can be used as a highly sensitive detection system to identify small changes in cytosolic free $\mathrm{Ca}^{2+}$ levels. The hepatocytes from control and ethanol-fed rats differed significantly $(P<0.05)$ in total phosphorylase activity $(256 \pm 15$ and $154 \pm 12 \mathrm{nmol} / \mathrm{min}$ per mg of protein, respectively, for eight pairs), and the data in Fig. 3 are expressed as a fraction of the maximal activity as measured in the presence of AMP (5 mM) and 1,2-dimethoxyethane $(10 \%, v / v)[18]$. The dose-response curve for activation of phosphorylase in response to ethanol showed less sigmoidicity than the $\mathrm{Ca}^{2+}$ mobilization in indo-1-loaded cells, and a significanty elevation of phosphorylase levels could be detected with ethanol concentrations of $15 \mathrm{~mm}$ and above. No significant differences were evident in the phosphorylase-activation response 


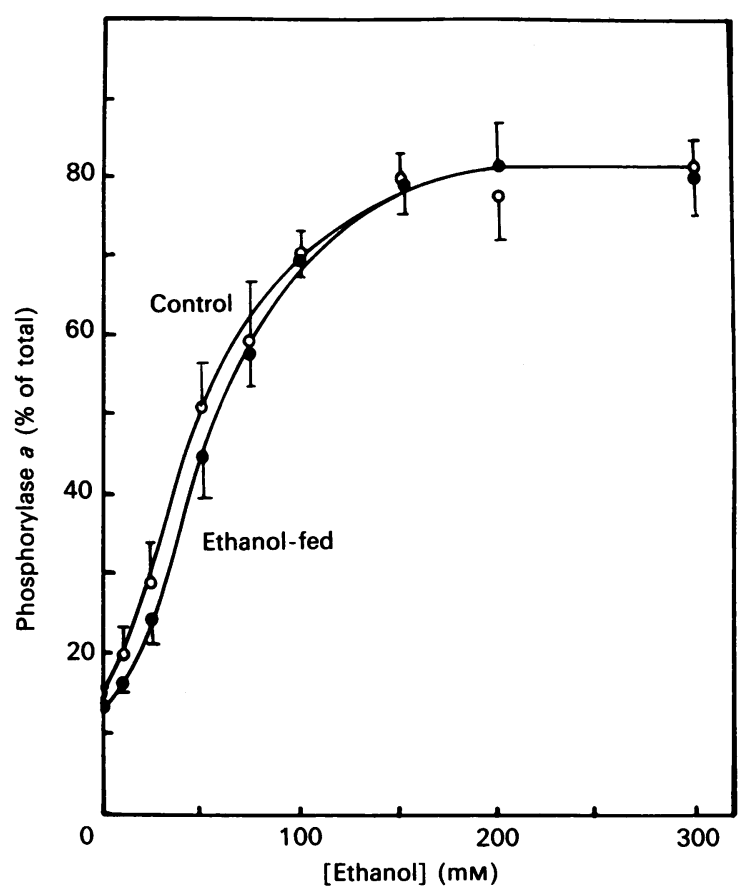

Fig. 3. Ethanol-induced activation of phosphorylase in isolated hepatocytes from ethanol-fed and control rats

Cells were preincubated for $30 \mathrm{~min}$ before addition of ethanol in concentrations from 15 to $300 \mathrm{~mm}$. Samples were taken for phosphorylase assay $30 \mathrm{~s}$ after ethanol addition. Phosphorylase $a$ and total phosphorylase $(a+b)$ activities were measured, and the activity of phosphorylase $a$ was expressed as a percentage of the total. Results are means \pm S.E.M. for six to eight individual pairs.

in either preparation. Half-maximal phosphorylase activation was obtained at approx. $50 \mathrm{~mm}$, and maximally activated levels of phosphorylase required 150-200 mm-ethanol. These data are in agreement with earlier findings on hepatocytes from chow-fed rats [8]. It should be pointed out, however, that the data in Fig. 3 , measured at the peak of phosphorylase activation (30 s), do not reflect possible differences in the persistent activation of phosphorylase, owing to the slower decay of cytosolic $\mathrm{Ca}^{2+}$ in the cells from ethanol-fed rats. Similarly, other $\mathrm{Ca}^{2+}$-dependent enzymes not measured here could reflect this higher timeaveraged $\mathrm{Ca}^{2+}$ concentration in the preparations from ethanolfed rats.

In further experiments, we confirmed that the ethanol-induced $\mathrm{Ca}^{2+}$ mobilization in hepatocytes from ethanol-fed rats was associated with the activation of phospholipase C. Table 1 compares the formation of $\operatorname{Ins}(1,4,5) P_{3}$ during a $20 \mathrm{~s}$ reaction period in response to ethanol $(300 \mathrm{mM})$ or vasopressin (40 and $2 \mathrm{nM}$, representing saturating and half-saturating hormone levels respectively) in hepatocytes from ethanol-fed and control animals. As shown previously [8], a linear rate of formation of $\operatorname{Ins}(1,4,5) P_{3}$ is maintained for about $20 \mathrm{~s}$ after addition of these agonists. The response to $2 \mathrm{nM}$-vasopressin was comparable with that found with $300 \mathrm{~mm}$-ethanol, in agreement with previous results on hepatocytes from chow-fed rats [8]. The Ins $(1,4,5) P_{3}$ formation induced by $40 \mathrm{nM}$-vasopressin was somewhat $(25 \%)$ less in the cells from ethanol-fed animals compared with control preparations, but these differences were not statistically significant at the $5 \%$ level.

The data shown above indicate that the hepatocytes from ethanol-fed and control rats do not show a significant difference in their sensitivity to ethanol with respect to the stimulation of phospholipase C. The protein complex associated with this
Table 1. Ins $(1,4,5) P_{3}$ formation in hepatocytes from ethanol-fed and control rats

Isolated hepatocytes were prelabelled for $90 \mathrm{~min}$ with $\left[{ }^{3} \mathrm{H}\right]$ inositol and stimulated with ethanol or vasopressin (reaction time $20 \mathrm{~s}$ ). Results are means \pm S.E.M. of three experiments. Untreated cells contained $334 \pm 118$ c.p.m./mg for control and $361 \pm 68$ c.p.m. $/ \mathrm{mg}$ for ethanol-fed rats (not significantly different).

\begin{tabular}{lcc}
\hline & \multicolumn{2}{c}{$\begin{array}{c}\text { Ins }(1,4,5) P_{3} \\
(\% \text { of untreated })\end{array}$} \\
\cline { 2 - 3 } Agonist & Control & Ethanol-fed \\
\hline None & 100 & 100 \\
Ethanol (300 mM) & $157 \pm 24.4$ & $172 \pm 20.2$ \\
Vasopressin (2 nM) & $210 \pm 40.0$ & $197 \pm 26.0$ \\
Vasopressin (40 nM) & $1250 \pm 260$ & $907 \pm 98$
\end{tabular}

transmembrane signal-transduction pathway is localized in the plasma membrane. We were therefore interested to determine whether the liver plasma membrane of the ethanol-fed rats had developed tolerance to the fluidizing effects of ethanol. Polokoff et al. [22] had previously reported that plasma membranes of cultured Reuber $\mathrm{H} 35$ hepatoma cells display increased membrane fluidity and tolerance to disordering by ethanol in vitro after chronic ethanol administration. Fig. 4 illustrates the effect of ethanol on the membrane molecular order in plasma-membrane phospholipid vesicles prepared from livers of control and ethanolfed rats, as detected by e.s.r. The plasma-membrane preparation was characterized by using 5 '-nucleotidase as a marker enzyme [15]. The preparations from control animals were disordered by 100 mm-ethanol to the same extent $(\Delta S=2.1 \%)$ as reported previously for microsomal and mitochondrial membrane preparations [5,6]. By contrast, the membranes from ethanolfed animals were not affected by addition of $100 \mathrm{~mm}$-ethanol, although $200 \mathrm{~mm}$-ethanol was able to induce a significant decrease in order parameter in these preparations, similar to the control preparations. The membranes from ethanol-fed rats also differed from the control preparations in that the baseline order parameter

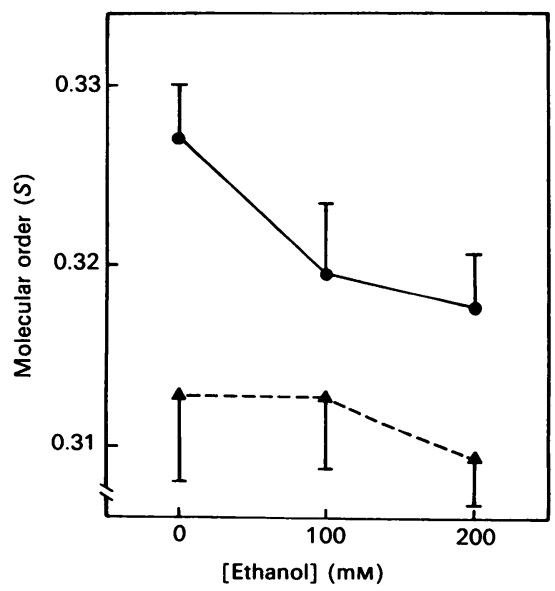

Fig. 4. Effect of ethanol in vitro on the molecular order parameter $(S)$ of liposomes prepared from liver plasma-membrane phospholipids of control $(\Theta)$ and ethanol-fed $(\Delta)$ rats, obtained by e.s.r. at $37^{\circ} \mathrm{C}$

Results were obtained from three different plasma-membrane preparations. Error bars are expressed as S.D. Differences in baseline order parameter (no ethanol) are statistically significant $(P<0.005)$ by a paired $t$ test. 
(i.e. in the absence of ethanol) was significantly lower. This behaviour is similar to that observed by Polokoff et al. [22] for hepatoma plasma membranes. In this respect, the plasma membranes are different from the microsomal and mitochondrial preparations, where the baseline order parameter was not found to be systematically affected by long-term ethanol feeding of the rat $[5,6]$. Similar results were obtained with intact liver plasma membranes from control and ethanol-fed rats (results not shown). This finding is consistent with previous results for erythrocytes and liver mitochondria from ethanol-fed rats, that membrane tolerance is a characteristic conferred by the phospholipids $[5,6]$. Taken together, the apparent lack of an adaptive response of the ethanol-induced phospholipase $\mathrm{C}$ activation in hepatocytes from ethanol-fed rats does not appear to result from a lack of alterations in the bulk physical properties of the plasma-membrane phospholipids.

\section{DISCUSSION}

The data presented in this paper raise significant questions, both mechanistically and physiologically, with regard to the ethanol-induced activation of the phosphoinositide-specific phospholipase C. Our earlier studies $[8,11,12]$ provided support for a model which emphasized the role of ethanol-membrane interactions in the activation of this signal-transduction process, in intact and permeabilized cells and in membrane preparations. The dose-response relationship of ethanol-induced $\mathrm{Ca}^{2+}$ mobilization covers the range of ethanol concentrations which causes detectable membrane-disordering effects $[8,11]$. Moreover, other membrane-active agents, including longer-chain alcohols and general anaesthetics, also activate phospholipase $\mathrm{C}$ in membrane preparations and cause an increase in cytosolic $\mathrm{Ca}^{2+}$ in intact cells, with an efficacy related to their ability to partition into the membrane $[8,11,12]$. The data presented here demonstrate that the adaptive responses which are reflected in the phenomenon of membrane tolerance in the liver plasma membrane do not shift the sensitivity to ethanol in phospholipase $\mathrm{C}$ activation. Mechanistic studies from our group on the turkey erythrocyte membrane indicated that ethanol may act on the G-protein involved in coupling the receptor conformational changes to the phospholipase C [11]. Specifically, ethanol is thought to affect the interaction of guanine nucleotides with the G-protein, promoting the release of GDP and the activation of phospholipase $C$ by the $\alpha$-subunit. This process takes place in a relatively polar part of the membrane, presumably near the membrane/water interphase. Ethanol may interact with this system by binding to a hydrophobic pocket on one of the proteins involved. Alternatively, ethanol and other organic solvents could alter the characteristics of membrane protein interaction in the polar phase of the membrane by affecting the physical parameters of the aqueous phase at the membrane surface. As we pointed out previously [8], the organic solvents that have been shown to be active in stimulating phospholipase $\mathrm{C}$ also affect the dielectric constant of the water in which they are dissolved. If this interpretation is correct, agents that would partition almost completely within the membrane would then be expected to affect the transmembrane signalling processes with different characteristics from those found for ethanol. Recent studies in our laboratory suggest this may, in fact, be valid (T. A. Rooney \& A. P. Thomas, unpublished work).

It should be pointed out that it is not unusual for ethanolsensitive processes to maintain their responsiveness to ethanol added in vitro, even after an adaptive response has been initiated in the animal by ethanol feeding. Many ethanol-sensitive enzymes show an alteration in their baseline activity in ethanol-fed animals which compensates for the effects of ethanol, so that the activity in the ethanol-fed animal exposed to acute ethanol would be comparable with the control activity in the absence of ethanol $[2,4]$. This pattern has been observed, for instance, in the adaptive response of the adenylate cyclase-coupled G-protein $G_{s}$, which is decreased after long-term ethanol treatment in vitro and in vivo [23]. The decrease in total phosphorylase activity in hepatocytes from ethanol-fed rats, which compensates in part for the ethanolinduced activation of this enzyme in hepatocytes (Fig. 3), could also be interpreted as an example of this response pattern. In an analogy to behavioural adaptive responses, this type of adaptation has been classified as 'physical dependence', since the removal of ethanol from the ethanol-fed animal would cause a marked difference in the basal activity of the ethanol-sensitive process. The ethanol-induced phospholipase $\mathrm{C}$ activation studied here differs from either the 'physical dependence' model or the 'tolerance' model in that the process shows no shift in sensitivity to ethanol, but also does not show evidence of a change in basal activity in response to sustained treatment in vivo with ethanol, at least as detected in the basal level of $\operatorname{Ins}(1,4,5) P_{3}$ or cytosolic $\mathrm{Ca}^{2+}$

Physiologically, the lack of an adaptive response of the phospholipase $\mathrm{C}$ activation to ethanol feeding raises the question of the significance of this action of ethanol for the control of liver metabolism. It is conceivable that the very transient nature of the stimulation of phospholipase $\mathbf{C}$ by ethanol permits the animal to forgo a physiological adjustment to this action of ethanol. However, recent studies from this laboratory (K. Higashi \& J. B. Hoek, unpublished work) show that the short-lived action of ethanol on phospholipase $\mathbf{C}$ does cause a significant alteration in the control of signal-transduction processes in the cell which can persist well after the $\mathrm{Ca}^{2+}$ response to ethanol has decayed. There is evidence that this persistent action of ethanol may, at least in part, be mediated by an activation of protein kinases in the cell, the effect of which appears to be reflected in an altered sensitivity to other agonists. This 'heterologous desensitization' by ethanol can remain in effect, even after the initial exposure to ethanol is past, because the recovery from ethanol treatment may depend on the activity of intracellular phosphatases.

The ethanol-sensitive phospholipase $\mathbf{C}$, by preserving its responsiveness after long-term ethanol feeding, could serve as a sensor mechanism for the maintenance of an adapted state in the ethanol-fed animal. Such a sensor system should $(a)$ be responsive to ethanol in the concentration range commonly encountered physiologically during ethanol intake, $(b)$ maintain its responsiveness even after long-term ethanol intake, and $(c)$ have the potential to initiate changes in the activity of a large number of cellular enzyme systems. Recent studies on cultured cells which adapt to long-term ethanol treatment in vitro indicate that this adaptation involves alterations in the control of gene expression $[23,24]$; it is conceivable that these alterations are mediated by protein kinases which are activated in response to a repeated stimulation of phospholipase $\mathrm{C}$ and other signalling processes by ethanol. The observation that the phospholipase $\mathrm{C}$ activation by ethanol is equally responsive in naive and ethanol-fed animals supports the view that this enzyme may be a potential candidate for the initiation and maintenance of adaptive responses in the cell.

We thank Shari Ackerman, Richard A. Hager and Janet B. Smith for excellent technical assistance. This study was supported by U.S. Public Health Service Grants AA07186, AA07215 and AA00088.

\section{REFERENCES}

1. Taraschi, T. F. \& Rubin, E. (1985) Lab. Invest. 52, 120-131

2. Tabakoff, B., Hoffman, P. L. \& Liljequist, S. (1987) Enzyme 37, 70-86 
3. Hoek, J. B. \& Taraschi, T. F. (1988) Trends Biochem. Sci. 13, 269-274

4. Hoek, J. B. \& Rubin, E. (1990) Alcohol Alcohol. 25, 143-156

5. Taraschi, T. F., Ellingson, J. S., Wu, A., Zimmerman, R. \& Rubin, E. (1986) Proc. Natl. Acad. Sci. U.S.A. 83, 9398-9402

6. Ellingson, J. S., Taraschi, T. F., Wu, A., Zimmerman, R. \& Rubin, E. (1988) Proc. Natl. Acad. Sci. U.S.A. 85, 3353-3357

7. Nie, Y., Stubbs, C. D., Williams, B. W. \& Rubin, E. (1989) Arch. Biochem. Biophys. 268, 349-359

8. Hoek, J. B., Thomas, A. P., Rubin, R. \& Rubin, E. (1987) J. Biol. Chem. 262, 682-691

9. Rubin, R., Ponnappa, B. C., Thomas, A. P. \& Hoek, J. B. (1988) Arch. Biochem. Biophys. 260, 480-492

10. Dorio, R. J., Hoek, J. B., Rubin, E. \& Forman, H. J. (1988) Biochem. Pharmacol. 37, 3528-3531

11. Rooney, T. A., Hager, R., Rubin, E. \& Thomas, A. P. (1989) J. Biol. Chem. 264, 6817-6822

12. Rubin, R. \& Hoek, J. B. (1988) Biochem. J. 254, 147-153

13. DeCarli, L. M. \& Lieber, C. S. (1967) J. Nutr. 91, 331-336

14. Bygrave, F. L. \& Trauter, C. J. (1978) Biochem. J. 174, 1021-1030

Received 2 April 1990/19 June 1990; accepted 11 July 1990
15. Prpic, V., Green, K. C., Blackmore, P. F. \& Exton, J. H. (1984) J. Biol. Chem. 259, 1382-1385

16. Arslan, P., DiVirgilio, F., Beltrame, M., Tsien, R. Y. \& Pozzan, T (1985) J. Biol. Chem. 260, 2719-2727

17. Gilboe, D. P., Larson, K. L. \& Nuttal, F. Q. (1972) Anal. Biochem. 47, 20-27

18. Uhing, R. J., Janski, A. M. \& Graves, D. J. (1979) J. Biol. Chem. 254, 3166-3169

19. Bligh, E. G. \& Dyer, W. J. (1959) Can. J. Biochem. Physiol. 37, 911-917

20. Taraschi, T. F., Wu, A. \& Rubin, E. (1985) Biochemistry 24 7096-7101

21. Hoek, J. B., Rubin, R. \& Thomas, A. P. (1988) Biochem. J. 251, 865-871

22. Polokoff, M. A., Simon, T. J., Harris, R. A., Simon, F. R. \& Iwahashi, M. (1985) Biochemistry 24, 3114-3120

23. Mochly-Rosen, D., Chang, F.-H., Cheever, L., Kim, M., Diamond, I. \& Gordon, A. S. (1988) Nature (London) 333, 848-850

24. Parent, L. J., Ehrlich, R., Matis, L. \& Singer, D. S. (1987) FASEB J. $1,469-473$ 